\title{
Article
}

\section{Androgen Glucuronidation in Mice: When, Where, and How}

\author{
Laurent Grosse ${ }^{1}$, Sarah Chouinard ${ }^{2}$, Sophie Pâquet ${ }^{1}$, Mélanie Verreault ${ }^{1}$, Jocelyn Trottier ${ }^{1}$, Alain Bélanger ${ }^{2}$ \\ and Olivier Barbier $1, * \mathbb{D}$
}

1 Centre Hospitalié Universitaire de Québec Research Center, Laboratory of Molecular Pharmacology, Endocrinology and Nephrology Axis, Faculty of Pharmacy, Laval University, Québec, QC G1V 0A6, Canada; laurent.grosse@univ-cotedazur.fr (L.G.); sophie.paquet.2@ulaval.ca (S.P.); melanie.verreault@crchudequebec.ulaval.ca (M.V.); jocelyn.trottier@crchudequebec.ulaval.ca (J.T.)

2 Centre Hospitalié Universitaire de Québec Research Center, Faculty of Medicine, Laval University, Québec, QC G1V 0A6, Canada; chouinardsarah@hotmail.com (S.C.); alain.belanger@fmed.ulaval.ca (A.B.)

* Correspondence: olivier.barbier@crchudequebec.ulaval.ca

check for updates

Citation: Grosse, L.; Chouinard, S.; Pâquet, S.; Verreault, M.; Trottier, J.; Bélanger, A.; Barbier, O. Androgen Glucuronidation in Mice: When, Where, and How. Biology 2022, 11 , 403. https://doi.org/10.3390/ biology11030403

Academic Editor: Paul S. Cooke

Received: 16 November 2021

Accepted: 3 March 2022

Published: 5 March 2022

Publisher's Note: MDPI stays neutral with regard to jurisdictional claims in published maps and institutional affiliations.

Copyright: (C) 2022 by the authors. Licensee MDPI, Basel, Switzerland. This article is an open access article distributed under the terms and conditions of the Creative Commons Attribution (CC BY) license (https:// creativecommons.org/licenses/by/ $4.0 /$ )
Simple Summary: Hormone metabolism can vary from one species to another. In humans, specific UDP-glucuronosyltransferase (UGT) enzymes transform androgens (the male hormones) into glucuronide derivatives, which are easier to eliminate. Whether a similar mechanism also takes place in mice has never been ascertained. This study aimed at addressing this question. Organs and pure Ugt $2 b$ enzymes from mice were assayed for their ability to transform several androgens into their glucuronide derivatives. Results show that, as in humans, both murine organs and enzymes are reactive with androgen molecules, and glucuronide derivatives are formed with substrate-, organand enzyme-specific manner. In conclusion, these observations revealed that glucuronosyltransferase enzymes from mice works in a similar manner as their human counterparts.

\begin{abstract}
Glucuronidation, catalyzed by UDP-glucuronosyltransferase UGT2B enzymes, is a major inactivating and elimination pathway for androgen hormones in humans. Whether Ugt2b enzymes from mice are also reactive with these hormones have never been investigated. The present study aimed at evaluating the capability of murine tissues and Ugt2b enzymes to glucuronidated androgens. The 7 murine Ugt2b (Ugt2b1, 2b5, 2b34, 2b35, 2b36, 2b37 and 2b38) enzymes were cloned and stably expressed into HEK293 cells. In vitro glucuronidation assays were performed with microsomal proteins or homogenates from mice tissues (liver, kidney, intestine, adipose, testis, prostate, epididymis, bulbo, seminal vesicle, mammary glands, uterus, and ovary) and from Ugt2b-HEK293 cells. Male and female livers, as well as male kidneys, are the major sites for androgen glucuronidation in mice. The male liver is highly efficient at glucuronidation of dihydrotestosterone (DHT) and testosterone and is enriched in Ugt2b1 and 2b5 enzymes. Androsterone and 3 $\alpha$-Diol are conjugated in the male kidney through an Ugt2b37-dependent process. Interestingly, castration partially abolished hepatic Ugt2b1 expression and activity, while Ugt2b37 was totally repressed. DHT injection partially corrected these changes. In conclusion, these observations revealed the substrate- and tissue-specific manner in which murine Ugt $2 b$ enzymes conjugate androgens. They also evidence how androgens modulate their own glucuronide conjugation in mice.
\end{abstract}

Keywords: androgen hormones; glucuronidation; UDP-glucuronosyltransferase; tissue distribution; kinetic parameters; liquid chromatography coupled with tandem mass spectrometry

\section{Introduction}

UDP-glucuronosyltransferase (UGT) enzymes catalyze the glucuronidation reaction, a conjugation process corresponding to the addition of the glucuronic moiety from the UDPglucuronic acid (UDPGA) co-substrate to various endogenous and exogenous molecules [1]. This reaction converts hydrophobic aglycons into highly polar molecules, and thus facilitates their removal from the human body in bile and urine [2]. Beyond their role in drug 
(as well as other exogenous compounds) metabolism, UGTs are also essential to the homeostatic equilibrium of numerous endogenous molecules, as varied as steroid and thyroid hormones, bile acids, retinoids and fatty acids [3].

Based on their amino acid sequence homology, UGTs are categorized into two families, namely UGT1 and UGT2 [4]. The UGT1 family comprises 1 subfamily, UGT1A, which is composed of nine members [5]. UGT2 enzymes are further divided into two sub-families, UGT2A and UGT2B [4]. In humans, the three UGT2A enzymes are expressed in the olfactive epithelium and liver and are generally associated to the inactivation of odorant molecules [4]. Seven human UGT2Bs have been identified (UGT2B4, 2B7, 2B10, 2B11, $2 \mathrm{~B} 15,2 \mathrm{~B} 17$, and 2B28) and are encoded by different genes, all clustered on chromosome 4q13-4q21.1 [4,5]. These enzymes are expressed in numerous tissues, including the liver, as well as steroid target tissues, such as the prostate, breast, skin, testis, and adipose tissue [3]. In mice, seven Ugt2b enzymes (Ugt2b1, 2b5, 2b34, 2b35, 2b36, 2b37, and 2b38) have also been identified $[6,7]$.

$\mathrm{C}_{19}$-steroids, such as testosterone, dihydrotestosterone (DHT), androsterone (ADT), and androstane- $3 \alpha, 17 \beta$-Diol ( $3 \alpha$-Diol) are preferentially conjugated by UGT2B7, 2B15, and 2B17. Among the numerous endobiotics that are known as substrates for UGT2Bs, androgens received particular attention during the last two decades [3,8-15]. This intense research effort first established the quantitative importance of androgen glucuronides in the human circulation where ADT-glucuronide (ADT-G) and $3 \alpha$-Diol-G are the most abundant androgen forms [16,17], and then identified the UGT2B7, 2B15 and $2 \mathrm{~B} 17$ isoforms as highly reactive in front of those androgens [3]. Indeed, UGT2B7 catalyzes glucuronide conjugation of the 3-hydroxyl position of androsterone and $3 \alpha$-Diol $[18,19]$, whereas the UGT2B15 isoform is stereoselective for the glucuronidation of the 17 $\beta$-hydroxyl position of testosterone, DHT and 3 $\alpha$-Diol [3]. By contrast, UGT2B17 is able to use both the 3hydroxyl position of ADT and 17 $\beta$-hydroxyl position of $3 \alpha$-Diol as an acceptor group for the glucuronosyl moiety [3].

While numerous evidences have pointed out glucuronidation and UGT enzymes as major controllers of androgen action and metabolism [10,15], mechanistic investigations are limited to cell cultures, since no appropriate animal models have been identified until now. Recent investigation demonstrated that, as humans, mice express Ugt2b enzymes (Ugt2b1, $2 \mathrm{~b} 5$, and 2b34-2b38) [6,7], suggesting that these animals possess a similar enzymatic equipment for androgen glucuronidation. The current study was therefore designed to analyze the ability of murine tissues to glucuronide androgens, and to decipher the contribution of each of the $7 \mathrm{Ugt} 2 \mathrm{bs}$ from mice in this metabolic reaction.

\section{Experimental Procedures}

\subsection{Materials}

UDP-glucuronic acid and all aglycons were obtained from Sigma (St. Louis, MO, USA) and ICN Pharmaceuticals, Inc. (Québec, QC, Canada). Lipofectin, Zeocin, and expression vectors were purchased from Invitrogen (Burlington, ON, Canada). Proteins assay reagents were obtained from Bio-Rad Laboratories, Inc. (Richmond, CA, USA). The Pfu Turbo DNA polymerase was obtained from Stratagene (La Jolla, CA, USA). Restriction enzymes and other molecular biology reagents were purchased from Roche Molecular Biochemicals (Indianapolis, IN, USA). Human embryonic kidney 293 cells (HEK293) were obtained from the American Type Culture Collection (Rockville, MD, USA). Ammonium formate was from Aldrich Chemical (Milwaukee, WI, USA), and high-performance liquid chromatography (HPLC)-grade methanol was provided by VWR Canlab (Montréal, QC, Canada).

\subsection{Animal Experiments and Tissue Collection}

Animal studies were performed in compliance with the Guidelines for Care and Use of Experimental Animals from the Canadian Council for Laboratory Animal Care. All experiments were approved by the Animal Care Council of the CHU de Québec Research Center (approbation number no. 12-078-1). Animals were housed in a $12 \mathrm{~h}$ daylight 
environment (12 h daylight cycle, lights off at 18:00 h) with food and water ad-libitum in the animal facility of the CHU de Québec Research Center. For gonadectomy studies, twelve 90-day old C57BL/6N male mice were castrated and received buprenorphine (Sigma Aldrich, Oakville, ON, Canada; $0.1 \mathrm{mg} / \mathrm{kg}$ ) on day 0 (surgery). Six male mice were sham-operated and were used as control. One day after surgery, and every following days for two weeks, six gonadectomized mice were injected subcutaneously with DHT $(0.1 \mathrm{mg} /$ day), while the remaining castrated animals, as well as the sham-operated ones, were injected with saline. At the end of the two-week experiment, isoflurane (Baxter Corporation, Mississauga, ON, Canada) was used to anesthetize the animals at sacrifice. Blood was collected through cardiac punctures and was added to $100 \mu \mathrm{L}$ EDTA (100 mM). Plasma was isolated by centrifugation at $3000 \mathrm{rpm}$ for $5 \mathrm{~min}$. Tissues were collected and freed from fat connective tissues immediately after death. Tissues were washed in $\mathrm{KCl}$ $1.15 \%$ and quickly frozen on dry iced. Tissues were kept at $-80{ }^{\circ} \mathrm{C}$ for subsequent RNA and protein isolations.

\subsection{RNA Isolation and Quantitative RT-PCR}

Total RNA was isolated from mice tissues $(20 \mathrm{mg})$ according to the TRI Reagent acid: phenol protocol as recommended by the supplier (Molecular Research Center Inc., Cincinnati, OH, USA). One $\mu \mathrm{g}$ of total RNA was reverse-transcribed using random hexamer primers (150 ng) and 200 units of Superscript II reverse-transcriptase according to manufacturer's instructions (Invitrogen, Burlington, ON, Canada).

Transcript levels of the seven Ugt2b were quantified through real time PCR experiments, using isoform-specific primers (Table 1), and a real-time PCR ABI Prism 7500 instrument from Applied Biosystems (Foster City, CA, USA). For each reaction, the final volume of $20 \mu \mathrm{L}$ was composed of $10 \mu \mathrm{L}$ of SYBR Green PCR mix, $2 \mu \mathrm{L}$ of each primer, and $6 \mu \mathrm{L}$ of a RT product diluted 1/50. Copy numbers were obtained through linear regression with a standard curve constructed with five log concentrations of each UGT2b cDNA. Integrity of the reverse transcription reaction was assessed by analyzing mRNA levels of the house keeping gene PPIA. Specificity of amplification for each Ugt2b was ensured by direct sequencing of PCR products.

Table 1. Primer sequences for real time PCR analyses of mouse Ugt2b.

\begin{tabular}{|c|c|c|c|}
\hline \multicolumn{4}{|c|}{ Real-Time Pcr Primers } \\
\hline & Forward & Reverse & Annealing Temperature \\
\hline PPIA & 5'-TCCTGGCATCTTGTCCATG-3' & 5'-CATCCAGCCATTCAGTCTTG-3' & $54{ }^{\circ} \mathrm{C}$ \\
\hline Ugt2b1 & 5'-TATGTTGCAGGTGTTGCT-3' & 5'-GTCCCAGAAGGTTCGAAC-3' & $60{ }^{\circ} \mathrm{C}$ \\
\hline Ugt2b5 & 5'-GGGACTCATTTTACAGTGAG-3' & 5'-CATGTTACTAACCATTGACC-3' & $56^{\circ} \mathrm{C}$ \\
\hline Ugt2b34 & 5'-AGCCCCTGCCTAAGGAAATA-3' & 5'-GAGTGTTGGAGCCCAATGTC-3' & $60^{\circ} \mathrm{C}$ \\
\hline Ugt2b35 & 5'CCAGACATTTACAGAGAAGG-3' & 5'CTGTCATGTTACTGACCATC-3' & $60{ }^{\circ} \mathrm{C}$ \\
\hline Ugt2b36 & 5'-TTGTTCAGAGCTCTGGAGAG-3' & 5'-GATGACCAAGAAGATCATTT-3' & $56^{\circ} \mathrm{C}$ \\
\hline Ugt2b37 & 5'-ATTTGGAGTTTCCTCACCCGA-3' & 5'-TAGATTGCCTCATAGACACTG-3' & $60{ }^{\circ} \mathrm{C}$ \\
\hline Ugt2b38 & 5'-GCAACTTTAGGACACAATACG-3' & 5'-ACTTCCTCCAGTGCATTGAGT-3' & $60^{\circ} \mathrm{C}$ \\
\hline
\end{tabular}

\subsection{Murine Ugt2b cDNA Cloning and Stable Expression in HEK293 Cells}

UGT2b constructs were obtained through PCR amplification using isoform-specific primers designed to generate PCR products comprising the previously reported open reading frames. NheI and XhoI restriction sites were added to the $5^{\prime}$-untranslated extremity of forward and reverse primers, respectively (Table 2). cDNA amplification was performed using Pfu Turbo Polymerase enzyme (Stratagene; Bellingham, WA, USA) and a GeneAmp PCR 9700 system (ThermoFisher Scientific; Waltham, MA, USA) in the presence of $2 \mu \mathrm{L}$ of RT products synthesized from the male mouse liver. PCR products were subsequently 
purified using the QIAquick ${ }^{\circledR}$ PCR Purification Kit (Qiagen, Mississauga, ON, Canada) and inserted into the $\mathrm{pCR}^{\circledR} \mathrm{II}-\mathrm{TOPO}{ }^{\circledR}$ (ThermoFisher Scientific; Waltham, MA, USA) vector, as recommended by the supplier. These Ugt2b cDNA were sub-cloned into the NheI/XhoI digested pcDNA4 vector (ThermoFisher Scientific; Waltham, MA, USA) with the Rapid DNA Ligation Kit (Roche; Mississauga, ON, Canada). Thereafter, plasmids encoding Ugt2b1, $2 \mathrm{~b} 5,2 \mathrm{~b} 34,2 \mathrm{~b} 35,2 \mathrm{~b} 36,2 \mathrm{~b} 37$, and 2b38 ( $2 \mu \mathrm{g})$ were transfected into HEK293 cells using the Lipofectamine reagent (ThermoFisher Scientific; Waltham, MA, USA) as recommended by the supplier. Stable Ugt2b-expressing clones were selected for 1 month with Zeocin $(32.5 \mu \mathrm{g} / \mathrm{mL}$; ThermoFisher Scientific; Waltham, MA, USA).

Table 2. Primer used for Ugt2b cDNA cloning (restriction sites are underlined).

\begin{tabular}{|c|c|c|c|}
\hline Primer & Sequence & RefSeq & Full Length cDNA \\
\hline Ugt2b1 NheI Forward & 5'-CTAGGCTAGCATCTAGTCAGTGATGTGGTTAGAAG & \multirow{2}{*}{ AC119816.5 } & \multirow{2}{*}{$2560 \mathrm{bp}$} \\
\hline Ugt2b1 XhoI Reverse & 5'-TCGACTCGAGCAGGACTCTCTGCTTCAGCCTTCAT & & \\
\hline Ugt2b5 NheI Forward & 5'-CTAGGCTAGCAGCAAATGGACTGTGAGAGAAGGAT & \multirow{2}{*}{ NM_009467.3 } & \multirow{2}{*}{$1901 \mathrm{bp}$} \\
\hline Ugt2b5 XhoI Reverse & 5'-TCGACTCGAGAGGCTGAAAGTTTGTTCATGTAGTT & & \\
\hline Ugt2b34 NheI Forward & 5'-CTAGGCTAGCGCCTGAAGTTAACCAA & \multirow{2}{*}{ NM_153598.2 } & \multirow{2}{*}{3048 bp } \\
\hline Ugt2b34 Xhol Reverse & 5'-TCGACTCGAGTGAAGGACCCTAAATCATTGCCTCC & & \\
\hline Ugt2b35 NheI Forward & 5'-CTAGGCTAGCGTTAACAGAAGCCCTTTGAC & \multirow{2}{*}{ NM_172881.3 } & \multirow{2}{*}{$3358 \mathrm{bp}$} \\
\hline Ugt2b35 XhoI Reverse & 5'-TCGACTCGAGTTCTTCCTTTTCTTTGCC & & \\
\hline Ugt2b36 NheI Forward & 5'-CTAGGCTAGCACTCTGAAGAGAAGAACA & \multirow{2}{*}{ NM_001029867.1 } & \multirow{2}{*}{$1888 \mathrm{bp}$} \\
\hline Ugt2b36 Xhol Reverse & 5'-TCGACTCGAGATGCATTATCAATGAGT & & \\
\hline Ugt2b37 NheI Forward & 5'-CTAGGCTAGCGCAAATGAACTGTGAAGAGAAGGAT & \multirow{2}{*}{ AC100269.7 } & \multirow{2}{*}{$1879 \mathrm{bp}$} \\
\hline Ugt2b37 Xhol Reverse & 5'-TCGACTCGAGAAATAGATGGGATTTTTGAAAATGC & & \\
\hline Ugt2b38 NheI Forward & 5'-CTAGGCTAGCCCCACGCGTCCGGGATT & \multirow{2}{*}{ NM_133894.2 } & \multirow{2}{*}{$1894 \mathrm{bp}$} \\
\hline Ugt2b38 Xhol Reverse & 5'-TCGACTCGAGATGGATCAGTATCCACAGATTTAC & & \\
\hline
\end{tabular}

\subsection{Microsome Isolation, Western-Blotting, and Glucuronidation Assays}

Microsomes from human liver (Lot \# H0610) were from XenoTech (Kansas city, MO, USA). Tissues or Ugt2b-overexpressing HEK293 cells were homogenized with a polytron (Brinkmann Instruments, Inc., Westbury, NY, USA). Microsome pellets were extracted by differential centrifugation as previously described [20] and resuspended at a $5 \mu \mathrm{g} / \mu \mathrm{L}$ concentration.

For western-blotting, microsomal proteins $(5 \mu \mathrm{g})$ or cell/tissue homogenates $(25-50 \mu \mathrm{g})$ were size-separated on a 10\% SDS-polyacrylamide gel. Gels were transferred onto nitrocellulose membranes and probed with the anti-UGT2B (EL-93, dilution 1/2000), anti-actin $(1 / 5000)$ and anti-calnexin $(1 / 2000)$ antibodies as previously reported [21,22]. The homemade EL-93 (anti-UGT2B) was obtained as previously described [20]. An anti-rabbit IgG antibody coupled with peroxidase (dilution 1/10,000) (Amersham Pharmacia Biotech, Oakville, ON, Canada) was used as second antibody, and the resulting immunocomplexes were detected with ECL (ThermoFisher Scientific; Waltham, MA, USA) and exposed on a Hyperfilm $^{\mathrm{TM}}$ for $15 \mathrm{~s}$ (Kodak Corp., Rochester, NY, USA).

Glucuronidation assays were performed in the presence of 40-50 $\mathrm{\mu g}$ homogenates using the previously reported glucuronidation assay buffer [20]. All screening assays were performed in the presence of $100 \mu \mathrm{M}$ substrates (testosterone, DHT, ADT, $3 \alpha$-Diol or the positive control 4-methylumbelliferone) at $37^{\circ} \mathrm{C}$ for $1 \mathrm{~h}$ in a final volume of $100 \mu \mathrm{L}$. Assays were ended by adding $100 \mu \mathrm{L}$ of methanol with $0.02 \%$ butylated hydroxytoluene. Kinetic experiments were performed with the presence of increasing substrate concentrations $(1-200 \mu \mathrm{M})$. 


\subsection{Steroid Quantification}

The formation of glucuronide conjugates (DHT-[17]G, ADT-[3]G, $3 \alpha$-Diol-[3 or 17]G and 4-MU-G) was analyzed by liquid chromatography coupled with tandem mass spectrometry (LC/ESI-MS/MS) as already reported [19,23].

\subsection{Statistical Analysis}

All data are presented as mean \pm standard deviation (S.D.). The statistical significance of differences was determined through the Student $t$ test using the JMP V7.0.1 program (SAS Institute, Inc.; Cary, NC, USA).

\section{Results}

\subsection{Gender- and Tissue-Specific Androgen Glucuronidation and Ugt2b Expression in Mice}

The capability of murine tissues (namely the liver, kidney, intestine, adipose tissue, testis, prostate, epididymis, bulbo gland, and seminal vesicles) to convert androgens into glucuronides was evaluated using in vitro glucuronidation assays performed in the presence of $100 \mu \mathrm{M}$ of testosterone, DHT, ADT or $3 \alpha$-Diol (Figure 1A,B). These tissues were selected based on their reported ability to glucuronidated androgen hormones in humans [3,24]. The formation of androgen glucuronide was detected only with homogenates from liver (male and female) and kidney (male), while all other tissues were unable to glucuronidate any of the four hormones assayed (Figure 1A,B). In the same vein, while male kidney extracts were highly reactive to generate ADT-G and $3 \alpha$-Diol-3G (Figure 1A), those from female animals were unreactive toward those substrates (Figure 1B). Interestingly, the male liver was highly reactive for steroids, such as testosterone and DHT, while the formation of ADT-G, $3 \alpha$-Diol-3, and -17G only occurred at a three-fold lower rate (Figure 1A). Similarly, experiments performed with female livers lead to lower formation of $3 \alpha$-Diol-glucuronide conjugates ( $3 \alpha$-Diol-3 and -17G) than other glucuronides (Figure 1B). Moreover, DHT and testosterone were glucuronidated twice more in male than female samples, while the hepatic formation of ADT-G (3-fold) and 3 $\alpha$-Diol-3 and -17G (2-fold) sustained an inverse sex-related variation. Taken together, these observations indicate that, in mice, androgen glucuronidation might be restricted to the liver and kidney for males and only to the liver for female.

Subsequent western blot analyses confirmed that $\mathrm{Ugt} 2 \mathrm{~b}$ proteins are detected in homogenates from male and female livers, but only from male kidneys (Figure 1C-E). Moreover, Ugt $2 \mathrm{~b}$ proteins are more abundant in livers from male homogenates than in female ones (Figure 1C). To further confirm the tissue- and gender-specific manner in which murine Ugt $2 \mathrm{~b}$ enzymes are expressed, the same tissues were analyzed for Ugt $2 \mathrm{~b}$ mRNA levels using isoform-specific qRT-PCR determination (Figure 2). As indicated in Figure 2A, none of the transcripts was detected in peripheral tissues such as the adipose tissue, prostate, epididymis, bulbo, seminal vesicle, mammary gland, uterus and ovary (Figure 2A). Ugt2b1, Ugt2b5, Ugt2b34, and Ugt2b36 transcripts were detected in testis but only at a far lower level than in the liver (Figure 2A). In this last tissue, all transcripts were quantified in both male and female samples (Figure 2A), but with a certain level of variability (Figure 2B). Indeed, while female livers contained similar concentrations of Ugt2b1, Ugt2b5, Ugt2b34, and Ugt2b36 messengers, the male RNAs were particularly enriched in Ugt2b1 and Ugt2b5 transcripts. Nevertheless, the expression of Ugt2b37 and Ugt2b38 was low in liver from both sexes (Figure 2B). Interestingly, these two isoforms were the most abundantly detected in male kidneys, while being absent (Ugt2b37) or barely detected (Ugt2b38) in female kidney RNAs (Figure 2C). Finally, Ugt2b5 and Ugt2b34 mRNAs were also present in renal RNA samples, and in far higher concentrations in the male compared to female samples (Figure 2C).

Overall these observations reveal that in vitro glucuronidation occurs only in murine liver (male and female) and kidney (male) from mice, and accordingly with previous reports [6,7], reinforce the tissue- and gender-specific manner in which Ugt2b enzymes are expressed in this species. These data also suggest that selected Ugt $2 b$ enzymes may 
be responsible for the tissue-selective glucuronidation of androgens in the murine liver and kidney.

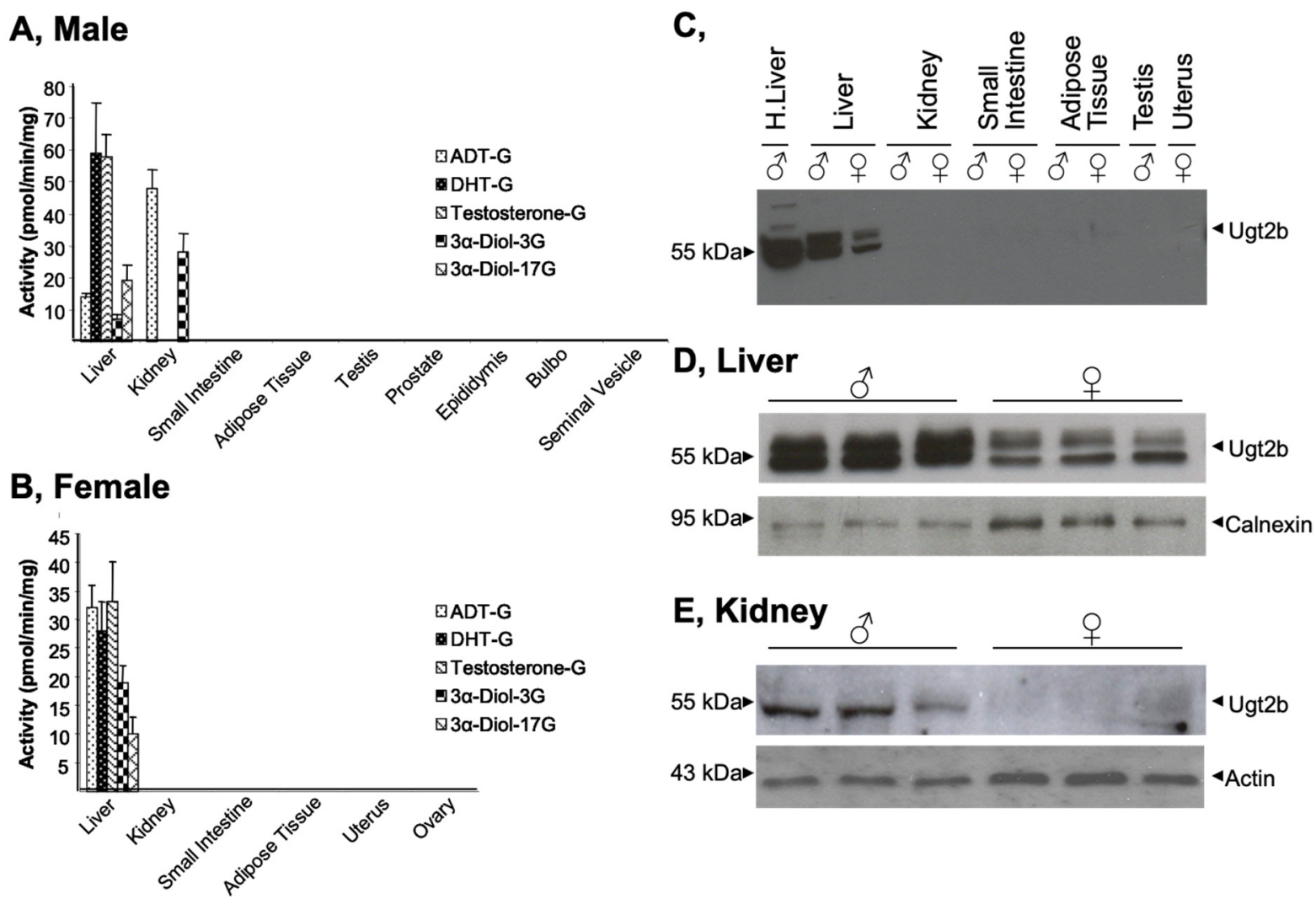

Figure 1. Tissue- and gender-specific distribution of Ugt2b expression and androgen-conjugating activities in mice. (A,B) Glucuronidation assays were performed with homogenates (40 $\mu \mathrm{g})$ of male (A) and female (B) murine tissues in the presence of $100 \mu \mathrm{M}$ of androgens for $1 \mathrm{~h}$. Assays were performed in triplicates with tissues from three animals. The formation of androgen glucuronides was quantified by LC-MS/MS analyses. (C-E) Tissue homogenates $(40 \mu \mathrm{g},(\mathbf{C}))$ or microsomal proteins $(5 \mu \mathrm{g} ;(\mathbf{D}, \mathbf{E}))$ were size-separated on $10 \%$ SDS-PAGE, transferred onto nitrocellulose membranes and hybridized with an anti-UGT2B (EL-93, 1/2000) antibody. (D,E) Membranes were subsequently immunoblotted with an anti-calnexin ((D) 1/2000) or an anti-actin ((E) 1/5000) antibody to ensure an equal loading of proteins in each lane. ADT: androsterone; DHT: dihydrotestosterone; $3 \alpha$-Diol: androstane- $3 \alpha, 17 \beta$-diol. Full western blot are provided as supplementary Figure S1.

\subsection{Androgen Selectivity of Murine Ugt2b Enzymes}

To evaluate the Ugt2b-dependent specificity of androgen glucuronidation in mice, we next cloned, stably expressed in human HEK293 cells, and evaluated the reactivity of each of the seven murine Ugt2b enzymes with androgen substrates (testosterone, DHT, ADT, and $3 \alpha$-Diol) and 4-methylumbelliferone (4-MU) (Figure 3). The presence of each enzyme in the corresponding Ugt2b-HEK293 cell line was assessed through western-blotting (Figure 3A). As expected, Ugt $2 \mathrm{~b}$ proteins showed different sizes reflecting variables sizes (from 529 to 532 amino acids), and the $\mathrm{N}$-glycosylation status as previously observed with other UGT enzymes [25] and all cell homogenates were reactive with the positive control substrate 4-MU (Figure 3B-H). The conversion of $3 \alpha$-Diol and ADT into their respective $3 \alpha$-Diol-3G and ADT-G derivatives was catalyzed at high levels only in the presence of homogenate from Ugt2b37-HEK293 cells (Figure 3G). While exhibiting the same substrate selectivity, Ugt $2 \mathrm{~b} 35$ only formed $3 \alpha$-Diol-3G and ADT-G at low levels (Figure $3 \mathrm{E}$ ). Ugt2b1 was the most active enzyme for the production of testosterone-G, DHT-G and 3 $\alpha$-Diol-17G (Figure 3B), while Ugt $2 \mathrm{~b} 5$ and Ugt $2 \mathrm{~b} 34$ were also able to generate these glucuronide derivatives but at 
lower levels (Figure 3C,D). Interestingly, all glucuronide derivatives were detected-but at low levels-when their unconjugated substrates were incubated in the presence of Ugt2b36HEK293 cell homogenates (Figure 3F). By contrast, Ugt2b38 was inefficient at converting any of the androgens assayed into their glucuronide conjugates (Figure $3 \mathrm{H}$ ).

A,

\begin{tabular}{|c|c|c|c|c|c|c|c|c|}
\hline & & $\underset{\text { Copies/ug RNA }}{\text { Ugt2b1 }}$ & $\underset{\text { Copies/ug RNA }}{\text { Ugt2b5 }}$ & $\begin{array}{l}\text { Ugt2b34 } \\
\text { Copies/ug RNA }\end{array}$ & $\begin{array}{l}\text { Ugt2b35 } \\
\text { copies/ug RNA }\end{array}$ & $\underset{\text { Copies/ug RNA }}{\text { Ugt2b36 }}$ & $\begin{array}{l}\text { Ugt2b377 } \\
\text { copies/ug RNA }\end{array}$ & $\begin{array}{l}\text { Ugt2b38 } \\
\text { copies/ug RNA }\end{array}$ \\
\hline 0 & \begin{tabular}{|l|} 
Liver \\
Kidney \\
SI \\
AT \\
Testis \\
Prostate \\
Epididymis \\
Bulbo \\
SV
\end{tabular} & $\begin{array}{c}3.61 \times 10^{5} \pm 2.0 \times 10^{4} \\
\text { ND } \\
\text { ND } \\
\text { ND } \\
6.22 \times 10^{2} \pm 5.7 \times 10^{1} \\
\text { ND } \\
\text { ND } \\
\text { ND } \\
\text { ND }\end{array}$ & $\begin{array}{c}3.54 \times 10^{5} \pm 1.5 \times 10^{4} \\
6.65 \times 10^{3} \pm 2.0 \times 10^{2} \\
1.54 \times 10^{3} \pm 3.7 \times 10^{2} \\
\text { ND } \\
3.66 \times 10^{3} \pm 4.9 \times 10^{2} \\
\text { ND } \\
\text { ND } \\
\text { ND } \\
\text { ND }\end{array}$ & $\begin{array}{c}1.52 \times 10^{5} \pm 2.6 \times 10^{4} \\
6.96 \times 10^{3} \pm 2.3 \times 10^{2} \\
1.59 \times 10^{2} \pm 6.0 \times 10 \\
\text { ND } \\
1.40 \times 10^{3} \pm 8.6 \times 10^{1} \\
\text { ND } \\
\text { ND } \\
\text { ND } \\
\text { ND }\end{array}$ & $\begin{array}{c}1.95 \times 10^{4} \pm 2.6 \times 10^{3} \\
\text { ND } \\
\text { ND } \\
\text { ND } \\
\text { ND } \\
\text { ND } \\
\text { ND } \\
\text { ND } \\
\text { ND }\end{array}$ & $\begin{array}{c}1.43 \times 10^{5} \pm 3.2 \times 10^{4} \\
\text { ND } \\
\text { ND } \\
\text { ND } \\
1.49 \times 10^{3} \pm 2.9 \times 10^{2} \\
\text { ND } \\
\text { ND } \\
\text { ND } \\
\text { ND }\end{array}$ & $\begin{array}{c}5.91 \times 10^{2} \pm 3.1 \times 10^{1} \\
3.16 \times 10^{4} \pm 9.9 \times 10^{3} \\
\text { ND } \\
\text { ND } \\
\text { ND } \\
\text { ND } \\
\text { ND } \\
\text { ND } \\
\text { ND }\end{array}$ & $\begin{array}{c}2.66 \times 10^{3} \pm 3.4 \times 10^{2} \\
1.21 \times 10^{5} \pm 8.0 \times 10^{3} \\
\text { ND } \\
\text { ND } \\
\text { ND } \\
\text { ND } \\
\text { ND } \\
\text { ND } \\
\text { ND }\end{array}$ \\
\hline 9 & \begin{tabular}{|l} 
Liver \\
Kidney \\
SI \\
MG \\
Uterus \\
Ovary \\
\end{tabular} & \begin{tabular}{|c}
$4.26 \times 10^{4} \pm 1.1 \times 10^{4}$ \\
ND \\
ND \\
ND \\
ND \\
ND
\end{tabular} & \begin{tabular}{|c|}
$5.72 \times 10^{4} \pm 9.3 \times 10^{2}$ \\
ND \\
ND \\
ND \\
ND \\
ND
\end{tabular} & \begin{tabular}{|c}
$7.54 \times 10^{4} \pm 8.3 \times 10^{3}$ \\
$1.98 \times 10^{2} \pm 5.6 \times 10^{1}$ \\
ND \\
ND \\
ND \\
ND
\end{tabular} & \begin{tabular}{|c}
$6.20 \times 10^{3} \pm 8.9 \times 10^{2}$ \\
ND \\
ND \\
ND \\
ND \\
ND
\end{tabular} & \begin{tabular}{|c|}
$6.89 \times 10^{4} \pm 3.0 \times 10^{4}$ \\
ND \\
ND \\
ND \\
ND \\
ND
\end{tabular} & $\begin{array}{c}5.41 \times 10^{2} \pm 2.2 \times 10^{2} \\
\text { ND } \\
\text { ND } \\
\text { ND } \\
\text { ND } \\
\text { ND }\end{array}$ & \begin{tabular}{|c}
$6.21 \times 10^{1} \pm 2.43 \times 10$ \\
$6.09 \times 10^{1} \pm 1.48 \times 10$ \\
ND \\
ND \\
ND \\
ND
\end{tabular} \\
\hline
\end{tabular}

$B$, Liver

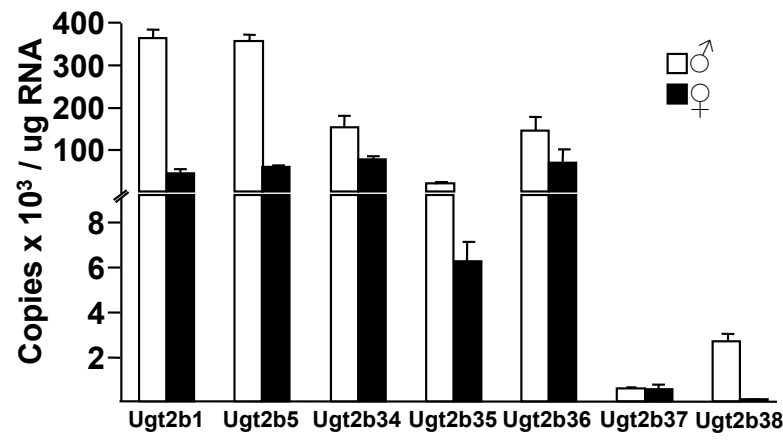

\section{C, Kidney}

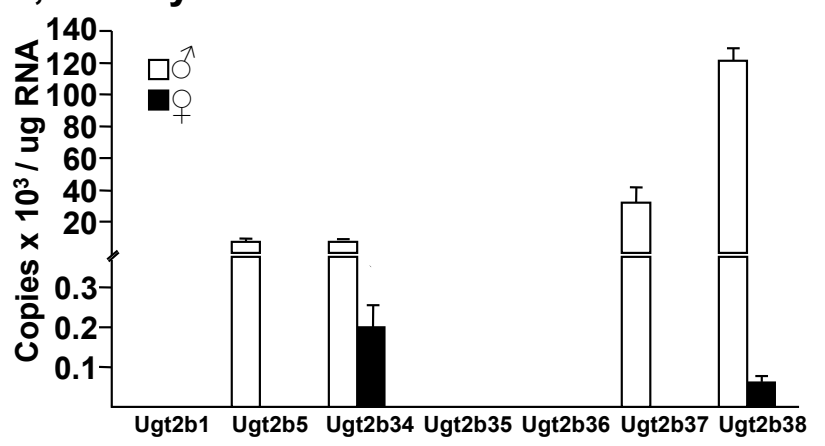

Figure 2. Tissue distribution of murine Ugt $2 b$ transcripts. Total RNA from male and female mice ( $n=3 /$ sex) tissues were extracted, reverse-transcribed, and analyzed for the expression of the seven Ugt2b enzymes through qRT-PCR analyses (Table 1). The Ugt2b copy numbers in all tissues (A) including Liver (B) and Kidney (C) were obtained using linear regression with a standard curve that included five log concentrations of the Ugt2b plasmids. Experiments were performed in triplicate. SI, small intestine; AT, adipose tissue; SV, seminal vesicle; MG, mammary gland. ND: not detected.

Overall, these experiments point-out: (i) the Ugt2b1, 2b5, and $2 b 34$ enzymes as the potential contributors of the elevated rates of testosterone-G, DHT-G, and 3 $\alpha-$ Diol-17G formation in the presence of liver extracts (Figure 1A,B); and (ii) the Ugt2b37 enzyme as the probable catalyzer of ADT-G and $3 \alpha$-Diol-3G formation in male kidney (Figure 1A). To investigate such a possibility, we determined and compared the kinetic parameters of androgen glucuronidation by microsomes from male liver and kidney samples or Ugt2bHEK293 cells (Table 3). When assayed for testosterone glucuronidation, liver and Ugt2b1 extracts exhibited similar affinity $\left(\mathrm{K}_{\mathrm{M}}\right)$ values of $29.2 \pm 1.7 \mu \mathrm{M}$ and $20.3 \pm 0.7 \mu \mathrm{M}$, respectively. By contrast, the affinity of the Ugt2b5 enzyme $(65.5 \pm 8.6 \mu \mathrm{M})$ was two-times lower when compared to the liver. Similarly, Ugt2b1 also had the closest $\mathrm{K}_{\mathrm{M}}$ values for DHT when compared to the liver $(17.8 \pm 0.7$ and $24.1 \pm 1.0 \mu \mathrm{M}$, respectively), while Ugt2b5 $(35.6 \pm 11.5 \mu \mathrm{M})$ and Ugt2b34 (54.9 $\pm 2.9 \mu \mathrm{M})$ exhibited lower affinities (Table 3). Interestingly, microsomal proteins purified from the murine liver $\left(\mathrm{K}_{\mathrm{M}}=19.3 \pm 2.0 \mu \mathrm{M}\right)$ and from HEK293 expressing Ugt2b1 $\left(\mathrm{K}_{\mathrm{M}}=17.8 \pm 2.0 \mu \mathrm{M}\right), \mathrm{Ugt} 2 \mathrm{~b} 5\left(\mathrm{~K}_{\mathrm{M}}=22.5 \pm 5.1 \mu \mathrm{M}\right)$ or Ugt2b34 $\left(\mathrm{K}_{\mathrm{M}}=16.3 \pm 4.8 \mu \mathrm{M}\right)$ exhibited all similar values for the conversion of $3 \alpha$-Diol into $3 \alpha$-Diol-17G (Table 3). Finally, kidney and Ugt2b37-HEK293 cells also exhibited remarkable similar $K_{M}$ values for $3 \alpha$-Diol-3G and ADT-G conjugations (Table 3). 


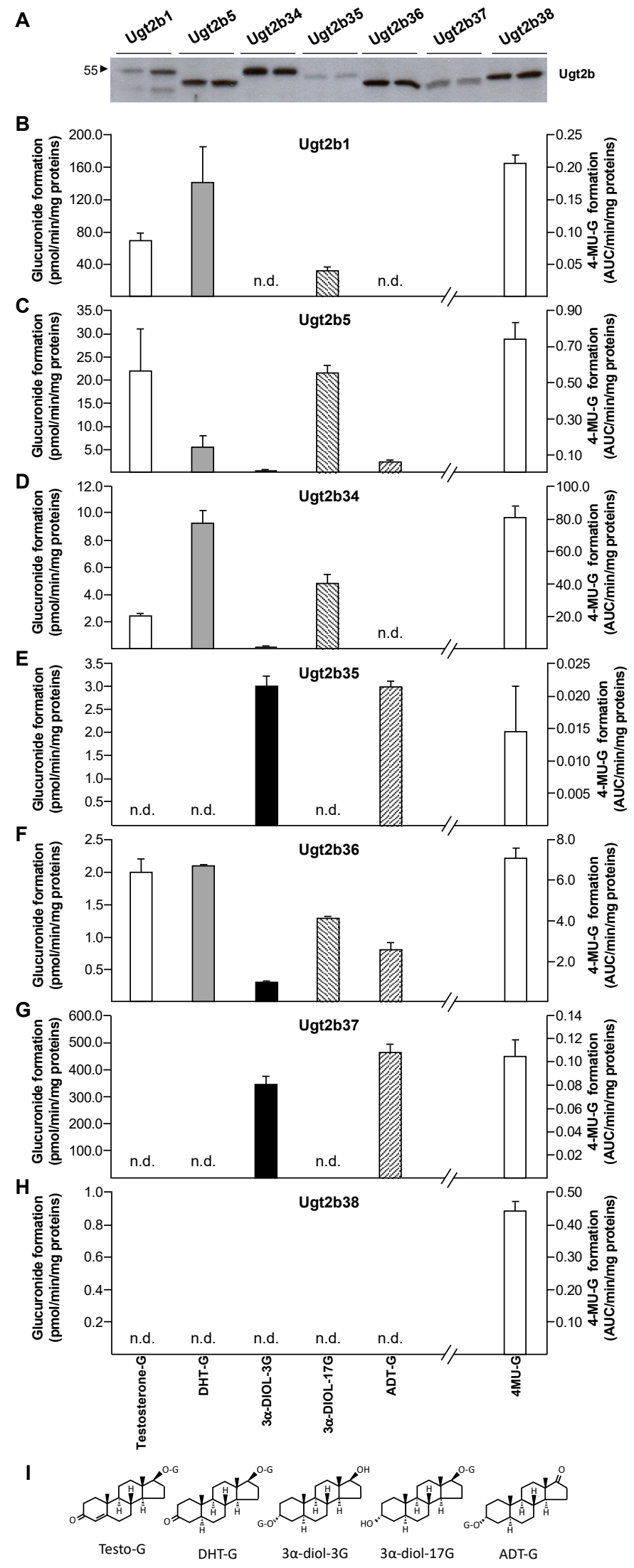

Figure 3. Stereoselectivity of male liver, kidney and recombinant murine Ugt2b enzymes for androgen glucuronidation. (A) Homogenates from Ugt2b-HEK293 cells ( $25 \mu \mathrm{g}$ ) were size separated on 10\% 
SDS-PAGE, transferred onto nitrocellulose membranes and hybridized with the anti-UGT2B (EL-93; 1/2000). (B-H) Homogenates (50 $\mu \mathrm{g})$ from Ugt2b1- (B), 2b5- (C), 2b34- (D), 2b35- (E), 2b36- (F), 2b37- (G), and 2b38-HEK293 (H) cells were incubated in a glucuronidation assay buffer for $1 \mathrm{~h}$ in the presence of $100 \mu \mathrm{M}$ of androsterone (ADT), dihydrotestosterone (DHT), testosterone, androstane-3 $\alpha$, $17 \beta$-diol ( $3 \alpha$-Diol), or 4-methylumbelliferone (4-MU, positive control). Glucuronidated products were quantified by LC-MS/MS analyses. (I) Numbered structures are illustrated. Data represent the mean of two experiments performed in triplicate. Nd: not detected. Full western blot are provided in supplementary Figure S2.

Table 3. Kinetic parameters of androgens glucuronidation by microsomal proteins from male liver, kidney, and recombinant Ugt2b proteins.

\begin{tabular}{|c|c|c|c|}
\hline Androgen-Glucuronide & Tissue/Enzyme & $\begin{array}{c}\text { Vmax app } \\
\text { (pmol/min/mg Proteins) }\end{array}$ & $\begin{array}{c}\mathrm{K}_{\mathrm{M}} \\
(\mu \mathrm{M})\end{array}$ \\
\hline \multirow{3}{*}{ Testosterone-G } & Liver & $1611.3 \pm 56.1$ & $29.2 \pm 1.7$ \\
\hline & Ugt2b1 & $51.2 \pm 1.5$ & $20.3 \pm 0.7$ \\
\hline & Ugt2b5 & $186.5 \pm 1.0$ & $65.5 \pm 8.6$ \\
\hline \multirow{4}{*}{ DHT-G } & Liver & $3987.0 \pm 95.5$ & $24.1 \pm 1.0$ \\
\hline & Ugt2b1 & $238.5 \pm 0.3$ & $17.8 \pm 0.7$ \\
\hline & Ugt2b5 & $50.5 \pm 2.1$ & $35.6 \pm 11.5$ \\
\hline & Ugt2b34 & $43.1 \pm 1.7$ & $54.9 \pm 2.9$ \\
\hline \multirow[t]{4}{*}{$3 \alpha$-Diol-17G } & Liver & $485.3 \pm 24.5$ & $19.3 \pm 2.0$ \\
\hline & Ugt2b1 & $34.8 \pm 1.7$ & $11.7 \pm 2.0$ \\
\hline & Ugt2b5 & $115.2 \pm 12.4$ & $22.7 \pm 5.1$ \\
\hline & Ugt2b34 & $8.5 \pm 0.6$ & $16.3 \pm 4.8$ \\
\hline \multirow[t]{2}{*}{$3 \alpha$-Diol-3G } & Kidney & $215.9 \pm 2.9$ & $2.0 \pm 0.1$ \\
\hline & Ugt2b37 & $1774.1 \pm 51.6$ & $3.9 \pm 1.5$ \\
\hline \multirow[t]{2}{*}{ ADT-G } & Kidney & $262.8 \pm 2.2$ & $2.3 \pm 0.8$ \\
\hline & Ugt2b37 & $2091.0 \pm 50.8$ & $3.6 \pm 0.4$ \\
\hline
\end{tabular}

Results are expressed as mean \pm S.D. of 2 experiments performed in triplicate. $\mathrm{K}_{\mathrm{M}}$ : Michaelis constant; Vmax app apparent maximal velocity; ADT: androsterone; DHT: dihydrotestosterone; $3 \alpha$-Diol: androstane- $3 \alpha, 17 \beta$-diol.

Overall, these last observations identify Ugt2b1 and Ugt2b37 as the most active androgen glucuronidating enzymes in the murine liver and kidney, respectively.

\subsection{Androgens Control Their Own Glucuronidation in the Murine Liver and Kidney}

To evaluate whether androgens control their own glucuronidation in mice, we next investigated whether DHT also affects the expression and activity of the Ugt2b1 and Ugt2b37 enzyme in male mice liver and kidney. For this purpose, 90-day old animals were sham-operated or gonadectomized and/or injected with DHT ( $0.1 \mathrm{mg})$ (Figures 4 and 5). Accordingly to previous reports [7], castration resulted in a strong reduction of hepatic Ugt2b1 mRNA levels in liver extracts, while the renal mRNA content in Ugt2b37 transcripts was also reduced (Figure 4). In DHT-treated gonadectomized animals, hepatic Ugt2b1 and renal Ugt2b37 mRNA expression were only partially restored. In addition, glucuronidation assays reveal that gonadectomy caused a significant reduction of the formation of testosterone-G, DHT-G, and $3 \alpha$-Diol-17G by liver enzymes, and of $3 \alpha$-Diol-3G and ADT-G by renal proteins from homogenates (Figure 5). While DHT injections fully restored androgen glucuronidation in the kidney (Figure 5D,E), the hepatic formation of androgen glucuronides was higher than after castration but remained significantly reduced in sham-operated samples (Figure 5A-C).

Overall, these observations demonstrate that gonadal androgens have the potential of controlling their own hepatic and renal glucuronidation in mice. 

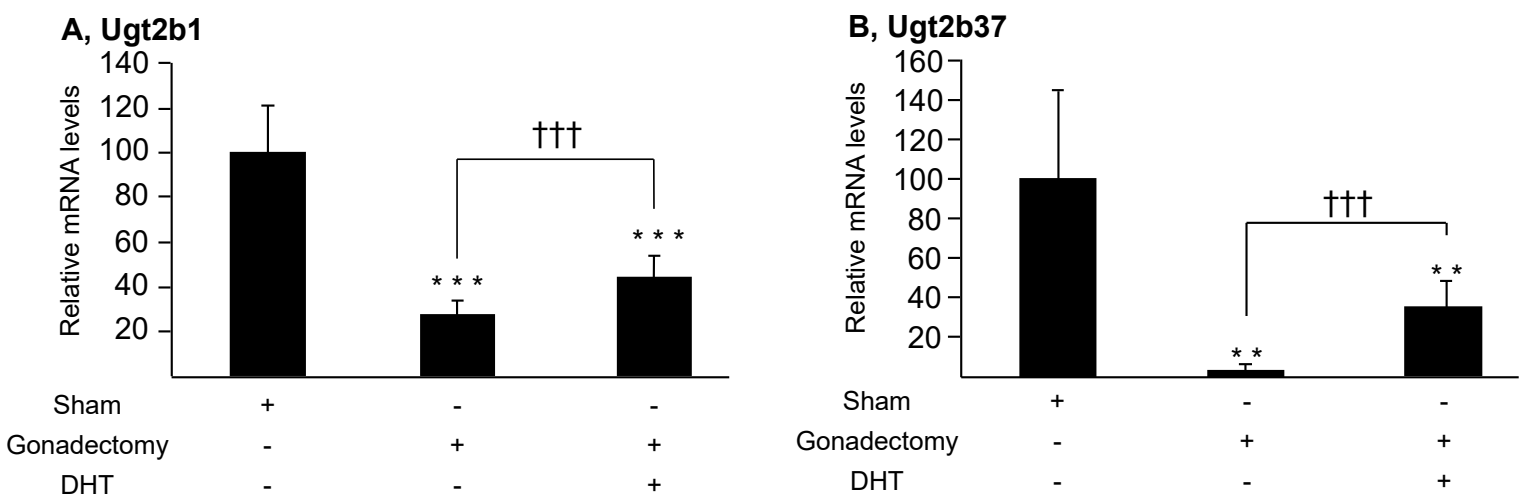

Figure 4. Gonadectomy and/or DHT differentially affect mRNA expression of the androgenconjugating Ugt2b1 and Ugt2b37 enzymes in male liver and kidney, respectively. Male mice (90 days old, $n=6$ /group) were either sham-operated (Sham), gonadectomized, and/or treated with $0.1 \mathrm{mg}$ DHT/day for 14 days, before euthanasia. Livers and kidneys were collected and subsequently investigated for Ugt2b1 (A) or Ugt2b37 (B) mRNA levels through qRT-PCR analyses. Ugt2b transcript copy numbers were obtained using linear regression with a standard curve that included five log concentrations of the corresponding Ugt $2 \mathrm{~b}$ plasmid and expressed as a percentage of copy numbers of control (sham) animals. Statistical analyses: Student's T test. ${ }^{* *}: p<0.005,{ }^{* * *}: p<0.001$ : versus sham; and ${ }^{++t}: p<0.001$ gonadectomized versus DHT-treated gonadectomized animals.
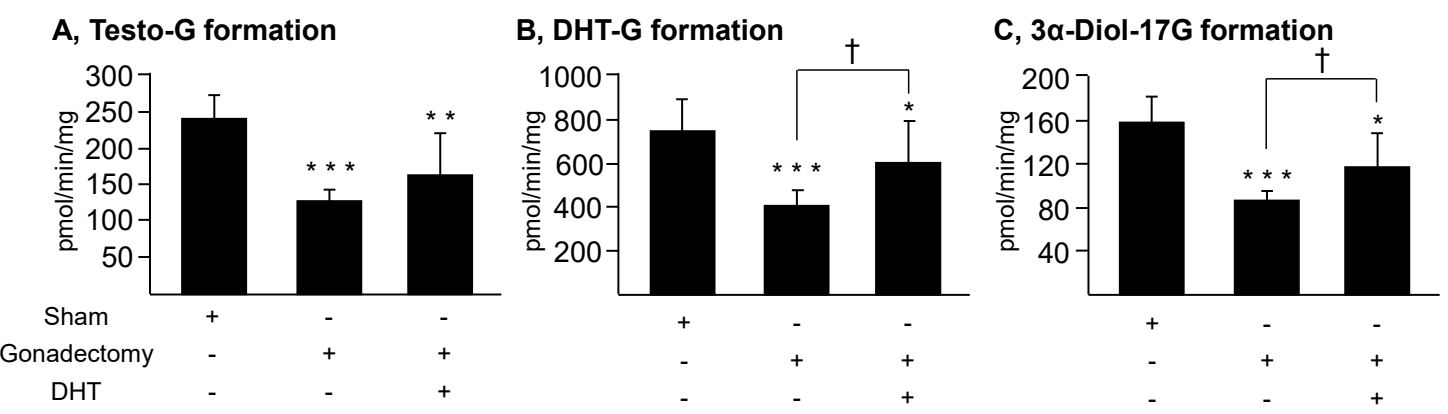

\section{D, 3a-Diol-3G formation}
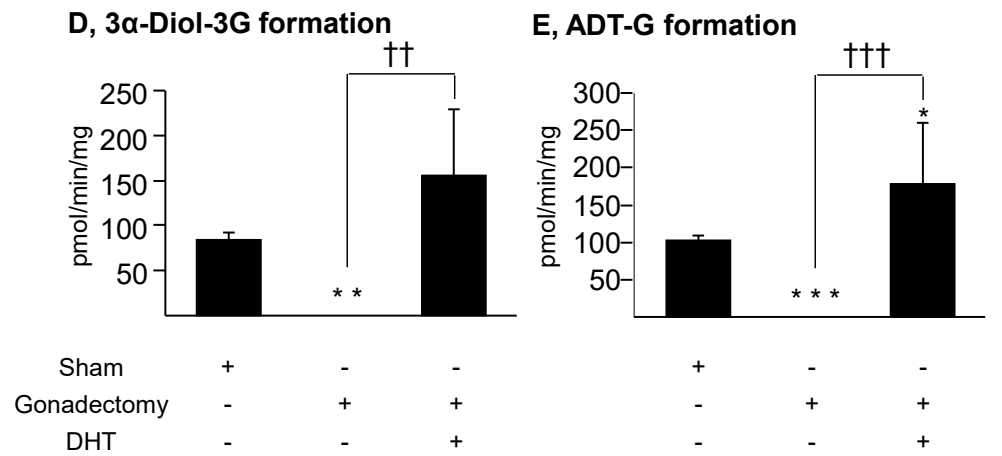

Figure 5. Gonadectomy and/or DHT differentially affect androgen glucuronidation in the male liver and kidney. Male mice (90 days old, $\mathrm{n}=6$ /group) were either sham-operated (sham), gonadectomized and/or treated with $0.1 \mathrm{mg} /$ day DHT for 14 days, before euthanasia. Livers and kidneys were collected, homogenized, and assayed for androgen glucuronidation as described in the materials and methods section. Glucuronidation assays were performed with liver (A-C) or kidney $(\mathrm{D}, \mathrm{E})$ homogenates in the presence of $100 \mu \mathrm{M}$ androgens for $1 \mathrm{~h}$. The formation of androgen glucuronides was quantified by LC-MS/MS analyses. Statistical analyses: Student $t$ test: *: $p<0.05$, ${ }^{* *}: p<0.005,{ }^{* * *}: p<0.001$ : versus sham; and ${ }^{+}: p<0.05,{ }^{++}: p<0.005,{ }^{+++}: p<0.001$ gonadectomized versus DHT-treated gonadectomized. ADT: androsterone; DHT: dihydrotestosterone; $3 \alpha-$ Diol: androstane- $3 \alpha, 17 \beta$-diol; G: glucuronide. 


\section{Discussion}

The present study provides the first comprehensive analysis of the expression and activity of murine Ugt $2 \mathrm{bs}$ in the control of androgen conjugation capabilities in mice. In vitro assays identified the liver as the main site for active androgen conjugation. These assays also revealed that kidney tissue is efficient at conjugating $5 \alpha$-reduced hormones, namely ADT and $3 \alpha$-Diol. We also evidenced that this stereo-selectivity for androgen glucuronidation reflects the differential expression of three enzymes: Ugt2b1 and Ugt2b5, which are expressed at high level in the liver and Ugt2b37 in the kidney.

The principal objective of the present study was to evaluate the contribution murine tissues and Ugt2bs in androgen glucuronidation. Our results clearly establish that, as human tissues and UGT2B enzymes [26], the murine liver and kidney, as well as the Ugt2b1 (liver) and Ugt2b37 (kidney) enzymes are highly reactive with these substrates, in vitro. In contrast to humans where ADT-G and $3 \alpha$-Diol-G are the most abundant circulating androgen forms [16,17], the murine plasma does not contain any detectable androgen glucuronide [16,17]. However, the present study establishes that this absence of circulating androgen glucuronide in mice cannot be attributed to the inability of the Ugt2b enzymatic machinery to conjugate androgens. Thus, such an absence may actually reflect other physiological differences between rodents and higher mammals. Accordingly, humans and mice also display major dissimilarities in terms of androgen hormone synthesis [24]. For example, in humans, both the gonads (with testosterone) and the adrenals (with DHEA and DHEA-S) contribute to the production of androgenic precursors, while in rodents, the unique source of active DHT comes from the gonadal secretion of testosterone (Reviewed in [24]). Together, these data show that the androgen physiology differs between rodents and humans, both in terms of hormone synthesis and metabolism, and results of the current study reveals that these differences are not linked to the glucuronidation reaction itself. Indeed, not only murine Ugt $2 \mathrm{~b}$ enzymes are able to use androgens as substrates, but their enzymatic properties are also close to those reported for human enzymes [3,20,22,25]. For example, the $\mathrm{K}_{\mathrm{M}}$ values for androgen glucuronidation by the human UGT2B7, UGT2B15 and UGT2B17 are in a micromolar range $[3,20,22,25]$ which resembles to those of the murine Ugt $2 \mathrm{~b}$ enzymes, as demonstrated in the present study. Even in terms of substrate stereospecificity, the murine enzymes resemble to human ones. For example, both murine Ugt2b1 and human UGT2B15 are highly selective glucuronidating enzymes for the 17 $\beta$-hydroxyl position of testosterone, DHT, and $3 \alpha$-Diol [3,22], while the high affinity of Ugt2b37 for using the $3 \alpha$-position of ADT and $3 \alpha$-Diol is similar to what is reported for the human UGT2B7 isoform, an enzyme highly expressed in the human kidney [3,18]. To summarize, the results presented here demonstrate that Ugt2b enzymes exhibit similar capabilities and properties for androgen glucuronidation as human isoforms.

Despite their enzymatic similarities, murine androgen-conjugating Ugt2b enzymes display a very restricted tissue-distribution of their expression when compared to human enzymes. Indeed, accordingly with previous investigations [6], our investigations revealed that murine Ugt2b enzymes are almost exclusively expressed in the liver and kidney and are absent from major androgen target tissues such as the prostate, adipose tissues or epididymis. Furthermore, even when assayed through in vitro glucuronidation experiments, these targets appears as androgen glucuronidating-deficient tissues. Numerous reports have previously demonstrated that even if the liver and kidney are important sites for androgen glucuronidation in humans, this conjugation reaction also takes place in several peripheral tissues, including those listed above (reviewed in [24]). Not only androgen glucuronidation takes place in human peripheral organs, but recent discoveries demonstrate that in human androgen target tissues, such as the prostate, glucuronidation serves as a termination mechanism for the androgen signaling $[26,27]$. In this context, the present demonstration that peripheral tissues are unable to glucuronidate androgens in mice highlight another major difference between the two species, as of controlling androgen signaling. 
Furthermore, the present study also demonstrates that the removal of the endogenous site of androgen production (i.e., gonadectomy) causes a drastic reduction in Ugt2b1 (liver) and Ugt2b37 (kidney) expression, resulting in a significant decrease of androgen glucuronidation capabilities in both tissues. Nevertheless, providing exogenous hormones (namely DHT) restored, at least partially, these parameters. Taken together, these observations suggest that androgens serve as positive regulators for Ugt2b1 and Ugt2b37 expression, and by so, are able to stimulate their own glucuronidation. Again, this situation differs from what has been reported in humans, where androgens and their nuclear receptor were identified has negative regulators of the expression of the androgen-conjugating UGT2B15 and UGT2B17 enzymes [26,27]. These observations therefore denote another major difference between human and murine Ugt $2 b$ enzymes, i.e., their differential response to androgen in terms of expression and activity.

\section{Conclusions}

In conclusion, the present investigations revealed the substrate- and tissue-specific manners in which murine Ugt $2 b$ enzymes conjugate androgens. They also evidence how androgens modulate their own glucuronide conjugation in mice and provide the first evidence of a species-specific manner in which androgens control UGT2B expression.

Supplementary Materials: The following supporting information can be downloaded at: https: / / www.mdpi.com/article/10.3390/biology11030403/s1, Figure S1: Full western blots of Figure 1; Figure S2: Full western blots of Figure 3.

Author Contributions: Participated in research design: L.G., A.B. and O.B.; Conducted experiments: L.G., S.C., S.P., M.V. and J.T.; Contributed to new reagents or analytic tools: J.T.; Performed data analysis: L.G. and O.B.; Wrote or contributed to the writing of the manuscript: L.G., S.C., S.P., M.V., J.T., A.B. and O.B.; L.G. and O.B. contributed equally to the completion of the manuscript. All authors have read and agreed to the published version of the manuscript.

Funding: This study was supported by grants from the Canadian Institute of Health Research (CIHR), the Canadian Foundation for Innovation (CFI), and the Natural Sciences and Engineering Research Council of Canada (NSERC). S. Caron is supported by a scholarship from the Bourse Didier Mouginot from the "Fondation du CHU de Québec" (Québec).

Institutional Review Board Statement: Animal studies were performed in compliance with the Guidelines for Care and Use of Experimental Animals from the Canadian Council for Laboratory Animal Care. All experiments were approved by the Animal Care Council of the CHU de Québec Research Center (approbation number no. 12-078-1, date of approval: 9 March 2009).

Informed Consent Statement: Not applicable.

Data Availability Statement: All data could be obtained upon request to the authors.

Acknowledgments: The authors are also grateful to Chantal Guillemette (Université Laval and CHU de Québec Research Center) for providing the glucuronidated and non-glucuronidated forms of androgens used in the present study.

Conflicts of Interest: The authors have no conflict of interest to disclose.

\section{Abbreviations}

ADT, androsterone, ADT-G, androsterone-glucuronide; AT, adipose tissue; $3 \alpha$-Diol, androstane$3 \alpha, 17 \beta$-Diol; DHT, dihydrotestosterone; HEK293, human embryonic kidney 293 cells; LC/ESIMS/MS, liquid chromatography coupled with tandem mass spectrometry; 4-MU, 4-methylumbelliferone; MG, mammary gland; SI, small intestine; SV, seminal vesicle; UDPGA, UDP-glucuronic acid; UGT, UDP-glucuronosyltransferase 


\section{References}

1. Tukey, R.H.; Strassburg, C.P. Human UDP-glucuronosyltransferases: Metabolism, expression, and disease. Annu. Rev. Pharmacol. Toxicol. 2000, 40, 581-616. [CrossRef] [PubMed]

2. Tephly, T.R.; Burchell, B. UDP-glucuronosyltransferases: A family of detoxifying enzymes. Trends Pharmacol. Sci. 1990, 11, 276-279. [CrossRef]

3. Turgeon, D.; Carrier, J.S.; Levesque, E.; Hum, D.W.; Belanger, A. Relative enzymatic activity, protein stability, and tissue distribution of human steroid-metabolizing UGT2B subfamily members. Endocrinology 2001, 142, 778-787. [CrossRef] [PubMed]

4. Mackenzie, P.I.; Bock, K.W.; Burchell, B.; Guillemette, C.; Ikushiro, S.; Iyanagi, T.; Miners, J.O.; Owens, I.S.; Nebert, D.W. Nomenclature update for the mammalian UDP glycosyltransferase (UGT) gene superfamily. Pharm. Genom. 2005, 15, 677-685. [CrossRef] [PubMed]

5. Guillemette, C.; Levesque, E.; Harvey, M.; Bellemare, J.; Menard, V. UGT genomic diversity: Beyond gene duplication. Drug Metab. Rev. 2010, 42, 24-44. [CrossRef] [PubMed]

6. Buckley, D.B.; Klaassen, C.D. Tissue- and gender-specific mRNA expression of UDP-glucuronosyltransferases (UGTs) in mice. Drug Metab. Dispos. 2007, 35, 121-127. [CrossRef] [PubMed]

7. Buckley, D.B.; Klaassen, C.D. Mechanism of gender-divergent UDP-glucuronosyltransferase mRNA expression in mouse liver and kidney. Drug Metab. Dispos. 2009, 37, 834-840. [CrossRef]

8. Barbier, O.; Belanger, A. Inactivation of androgens by UDP-glucuronosyltransferases in the human prostate. Best Pract. Res. Clin. Endocrinol. Metab. 2008, 22, 259-270. [CrossRef]

9. Zhang, H.; Basit, A.; Wolford, C.; Chen, K.F.; Gaedigk, A.; Lin, Y.S.; Leeder, J.S.; Prasad, B. Normalized Testosterone Glucuronide as a Potential Urinary Biomarker for Highly Variable UGT2B17 in Children 7-18 Years. Clin. Pharmacol. Ther. 2020, 107, 1149-1158. [CrossRef]

10. Levesque, E.; Labriet, A.; Hovington, H.; Allain, E.P.; Melo-Garcia, L.; Rouleau, M.; Brisson, H.; Turcotte, V.; Caron, P.; Villeneuve, L.; et al. Alternative promoters control UGT2B17-dependent androgen catabolism in prostate cancer and its influence on progression. Br. J. Cancer 2020, 122, 1068-1076. [CrossRef]

11. De Wilde, L.; Roels, K.; Van Renterghem, P.; Van Eenoo, P.; Deventer, K. Steroid profiling in urine of intact glucuronidated and sulfated steroids using liquid chromatography-mass spectrometry. J. Chromatogr. A 2020, 1624, 461231. [CrossRef] [PubMed]

12. Li, C.Y.; Gupta, A.; Gaborik, Z.; Kis, E.; Prasad, B. Organic Anion Transporting Polypeptide-Mediated Hepatic Uptake of Glucuronide Metabolites of Androgens. Mol. Pharmacol. 2020, 98, 234-242. [CrossRef] [PubMed]

13. Wang, R.; Hartmann, M.F.; Wudy, S.A. Targeted LC-MS/MS analysis of steroid glucuronides in human urine. J. Steroid Biochem. Mol. Biol. 2021, 205, 105774. [CrossRef]

14. Zimmer, B.M.; Howell, M.E.; Ma, L.; Enders, J.R.; Lehman, D.; Corey, E.; Barycki, J.J.; Simpson, M.A. Altered glucuronidation deregulates androgen dependent response profiles and signifies castration resistance in prostate cancer. Oncotarget 2021, 12, 1886-1902. [CrossRef] [PubMed]

15. Bhatt, D.K.; Basit, A.; Zhang, H.; Gaedigk, A.; Lee, S.B.; Claw, K.G.; Mehrotra, A.; Chaudhry, A.S.; Pearce, R.E.; Gaedigk, R.; et al. Hepatic Abundance and Activity of Androgen- and Drug-Metabolizing Enzyme UGT2B17 Are Associated with Genotype, Age, and Sex. Drug Metab. Dispos. 2018, 46, 888-896. [CrossRef] [PubMed]

16. Guillemette, C.; Hum, D.W.; Belanger, A. Levels of plasma C19 steroids and 5 alpha-reduced C19 steroid glucuronides in primates, rodents, and domestic animals. Am. J. Physiol. 1996, 271, E348-E353. [CrossRef]

17. Hsing, A.W.; Stanczyk, F.Z.; Belanger, A.; Schroeder, P.; Chang, L.; Falk, R.T.; Fears, T.R. Reproducibility of serum sex steroid assays in men by RIA and mass spectrometry. Cancer Epidemiol. Prev. Biomark. 2007, 16, 1004-1008. [CrossRef]

18. Sten, T.; Bichlmaier, I.; Kuuranne, T.; Leinonen, A.; Yli-Kauhaluoma, J.; Finel, M. UDP-glucuronosyltransferases (UGTs) 2B7 and UGT2B17 display converse specificity in testosterone and epitestosterone glucuronidation, whereas UGT2A1 conjugates both androgens similarly. Drug Metab. Dispos. 2009, 37, 417-423. [CrossRef]

19. Turgeon, D.; Chouinard, S.; Belanger, P.; Picard, S.; Labbe, J.F.; Borgeat, P.; Belanger, A. Glucuronidation of arachidonic and linoleic acid metabolites by human UDP-glucuronosyltransferases. J. Lipid Res. 2003, 44, 1182-1191. [CrossRef]

20. Beaulieu, M.; Levesque, E.; Hum, D.W.; Belanger, A. Isolation and characterization of a novel cDNA encoding a human UDP-glucuronosyltransferase active on C19 steroids. J. Biol. Chem. 1996, 271, 22855-22862. [CrossRef]

21. Chouinard, S.; Pelletier, G.; Belanger, A.; Barbier, O. Cellular specific expression of the androgen-conjugating enzymes UGT2B15 and UGT2B17 in the human prostate epithelium. Endocr. Res. 2004, 30, 717-725. [CrossRef] [PubMed]

22. Levesque, E.; Beaulieu, M.; Green, M.D.; Tephly, T.R.; Belanger, A.; Hum, D.W. Isolation and characterization of UGT2B15(Y85): A UDP-glucuronosyltransferase encoded by a polymorphic gene. Pharmacogenetics 1997, 7, 317-325. [CrossRef] [PubMed]

23. Chouinard, S.; Pelletier, G.; Belanger, A.; Barbier, O. Isoform-specific regulation of uridine diphosphate-glucuronosyltransferase 2B enzymes in the human prostate: Differential consequences for androgen and bioactive lipid inactivation. Endocrinology 2006, 147, 5431-5442. [CrossRef] [PubMed]

24. Barbier, O.; Belanger, A. The cynomolgus monkey (Macaca fascicularis) is the best animal model for the study of steroid glucuronidation. J. Steroid Biochem. Mol. Biol. 2003, 85, 235-245. [CrossRef]

25. Barbier, O.; Girard, C.; Breton, R.; Belanger, A.; Hum, D.W. N-glycosylation and residue 96 are involved in the functional properties of UDP-glucuronosyltransferase enzymes. Biochemistry 2000, 39, 11540-11552. [CrossRef] 
26. Gauthier-Landry, L.; Belanger, A.; Barbier, O. Multiple roles for UDP-glucuronosyltransferase (UGT)2B15 and UGT2B17 enzymes in androgen metabolism and prostate cancer evolution. J. Steroid Biochem. Mol. Biol. 2015, 145, 187-192. [CrossRef]

27. Chouinard, S.; Barbier, O.; Belanger, A. UDP-glucuronosyltransferase 2B15 (UGT2B15) and UGT2B17 enzymes are major determinants of the androgen response in prostate cancer LNCaP cells. J. Biol. Chem. 2007, 282, 33466-33474. [CrossRef] 